\title{
Canadian Public Health Agency Lessons on Using Choropleth Maps to Characterize Geographic Distribution of COVID-19 Data
}

\section{A Experiência das Agências Locais de Saúde Pública Canadianas com a Utilização de Mapas Coropléticos para COVID-19}

David GUILLETTE ${ }^{1}$, Julie STRATTON ${ }^{1}$, Monali VARIA ${ }^{1}$, Vivian CHAU $^{2}$, Lawrence C. LOHه ${ }^{1}$

Acta Med Port 2020 Dec;33(12):792-794 - https://doi.org/10.20344/amp.15056

Keywords: Canada; COVID-19; Data Visualization; Geographic Mapping; Maps as Topic; Public Health Surveillance

Palavras-chave: Canadá; COVID-19; Mapas; Mapeamento Geográfico; Vigilância em Saúde Pública; Visualização de Dados

\section{INTRODUCTION}

Throughout Canada's COVID-19 response, data use, access, and reporting have featured prominently in academic and media discourse..$^{1-4}$ While there may be regional variation in data collection and analysis based on community context, all provincial agencies appeared to approach data disclosure with a desire to find a balance between transparency where a public risk of transmission existed against the need to respect the privacy and confidentiality of impacted individuals and groups.

One example of data disclosed by Canadian public health agencies during the COVID-19 response revolved around the geographic distribution of COVID-19 cases. This broad theme encompassed a heterogenous collection of types of geographic data that might be publicly disclosed, ranging from maps of exposure locations to choropleth maps, a visualization tool that uses colour to illustrate spatial distribution of a variable, which can be used to compare incidence rates of different neighbourhoods.

In sharing such information, Canadian public health agencies weighed other factors beyond transparency against privacy, including public sentiment and political expectations, resourcing, the risk of labelling and stigma, and the use of such information to better target interventions. This commentary reviews the experience of a Canadian local public health agency in planning and development, implementation and use, and evaluation of geographic data during the organization's COVID-19 response.

\section{Concept and development}

Peel Public Health is a local health department that serves the Region of Peel, which counts over 1.4 million residents living in three communities in the western part of the Greater Toronto Area: the urban cities of Mississauga and Brampton, and the more rural community of Caledon. ${ }^{5}$

Despite being one of the relatively more impacted re- gions in the province of Ontario, as with all other Canadian jurisdictions that saw the outbreak arrive in March, the Peel community succeeded in flattening the curve and averting a worst case scenario during its first wave of COVID-19. The imposition of closures and curtailments in mid-March was followed by a gradual reopening of the community throughout the summer. On August 27, 2020, Peel Region had reported over 7500 cases of COVID-19 and 327 deaths related to COVID-19. ${ }^{6}$

Throughout the pandemic, Peel Public Health continued to bring online various data products that informed disease control measures, tracked the course of the pandemic, and kept the public informed. ${ }^{7}$ In addition to a data dashboard that provided a summary and breakdown of cases and deaths by various parameters and time, other products included weekly epidemiologic updates, and disclosures on long-term care outbreaks, among other products introduced as the pandemic went on. ${ }^{7,8}$

Following the peak of the first wave in May, questions around where community transmission was occurring and comparisons of Canada's response with other national responses raised political and public interest in geographic data. Local and provincial politicians notably began speaking about the need to identify "hotspots" in referring to parts or whole communities that had seen higher rates of COVID-19 activity. As with other large health units, Peel Public Health responded to this interest, though there was limited consistency in the data that was ultimately presented by different agencies.

In Peel, the released data was initially presented in a choropleth map that colour-coded neighbourhoods by relative incidence rate compared to the average incidence rate across the Region as a whole. This allowed identification of neighbourhoods that had higher, similar, and lower rates of COVID-19 among residents.

\footnotetext{
1. Region of Peel - Public Health and Dalla Lana School of Public Health. University of Toronto. Toronto. Canada.

2. Rotman Research Institute. Baycrest Health Sciences. Toronto. Canada.

$\triangle$ Autor correspondente: Lawrence C. Loh. lawrence.loh@peelregion.ca

Recebido: 07 de outubro de 2020 - Aceite: 07 de outubro de 2020 | Copyright $\odot$ Ordem dos Médicos 2020
} 
Choropleth maps: implementation, caveats, and considerations

Subsequent released data included a series of six choropleth maps, generated to communicate the spatial distribution of incidence rates in Peel. One map highlights the cumulative incidence rate from the initial onset to the most recent period. The remaining maps visualize the spatial distribution of COVID-19 incidence rates in Peel during the latest five one-week periods. These maps feature a shared multi-hue sequential color scheme and manual break classification. A common classification and color scheme allow the audience to compare areas between maps without needing to reference the legend on each map thus reducing interpretation errors. ${ }^{9}$ Choropleth maps are effective when the data displayed has been standardized to show a rate or ratio and is attached to enumeration units. The maps display incidence rates at the census tract, which are small geographic regions with $2500-8000$ inhabitants. ${ }^{10}$ Census tracts were selected as an optimal balance between detail and privacy (Fig.1). ${ }^{11,12}$

The use of choropleth maps is beset by several caveats. Firstly, it is critical that the audience understand that choropleth maps cannot be used to predict or confirm spatial patterns in the data. ${ }^{13,14}$ Secondly, while a choropleth map can be effective at identifying areas with high and low values for an observed variable, spatial statistics must be used to determine whether an observed spatial pattern is significant or the result of random chance. ${ }^{14,15}$

From an implementation perspective, Peel hosted relevant data and maps on ArcGIS Online (AGOL), a cloudbased mapping and analysis solution that can make maps, analyze data, and share and collaborate. ${ }^{16}$ The Region of Peel has previously used AGOL to host wide range of geospatial web-based content including open data, maps, applications, and dashboards, and once the COVID-19 choro- pleth maps were completed a dashboard was created and hosted on AGOL. This dashboard supplements the maps and presents additional information including notes on data sources, methods, and limitations. The dashboard also allows users to explore key indicators (e.g. total number of cases, total number of community cases, total number of institutional cases and total cases by period) within Peel and across standard (municipal, census tracts) and custom geographies.

\section{Experience and evaluation}

During the initial development of the tool, discussions revolved around several considerations. The risk of stigmatization and labelling was identified early on by officials, and even politicians spoke to their concerns around this up until a change in public sentiment. Geographic data from both Peel and the neighbouring city of Toronto reflected socioeconomic realities very readily, which may serve in the long run to perpetuate unwarranted judgements of the residents of those neighbourhoods. Many of the most impacted neighbourhoods in the city of Toronto, for example, were also the city's poorest neighbourhoods, where structural elements such as employment and living conditions drove greater exposure and rates of COVID-19 already compared to neighbourhoods with more socioeconomically advantaged residents.

Peel's approach in comparing incidence rates among neighbourhoods limited the value of the tool in communicating overall risk of exposure, as the map presented where cases of COVID-19 lived, as opposed to where they acquired the disease. This was different than other countries, such as South Korea, which published locations of exposure. ${ }^{17}$ This nuance required careful messaging to residents to avoid a false sense of security; disclaimers with the tool explained that people should adhere to precautions

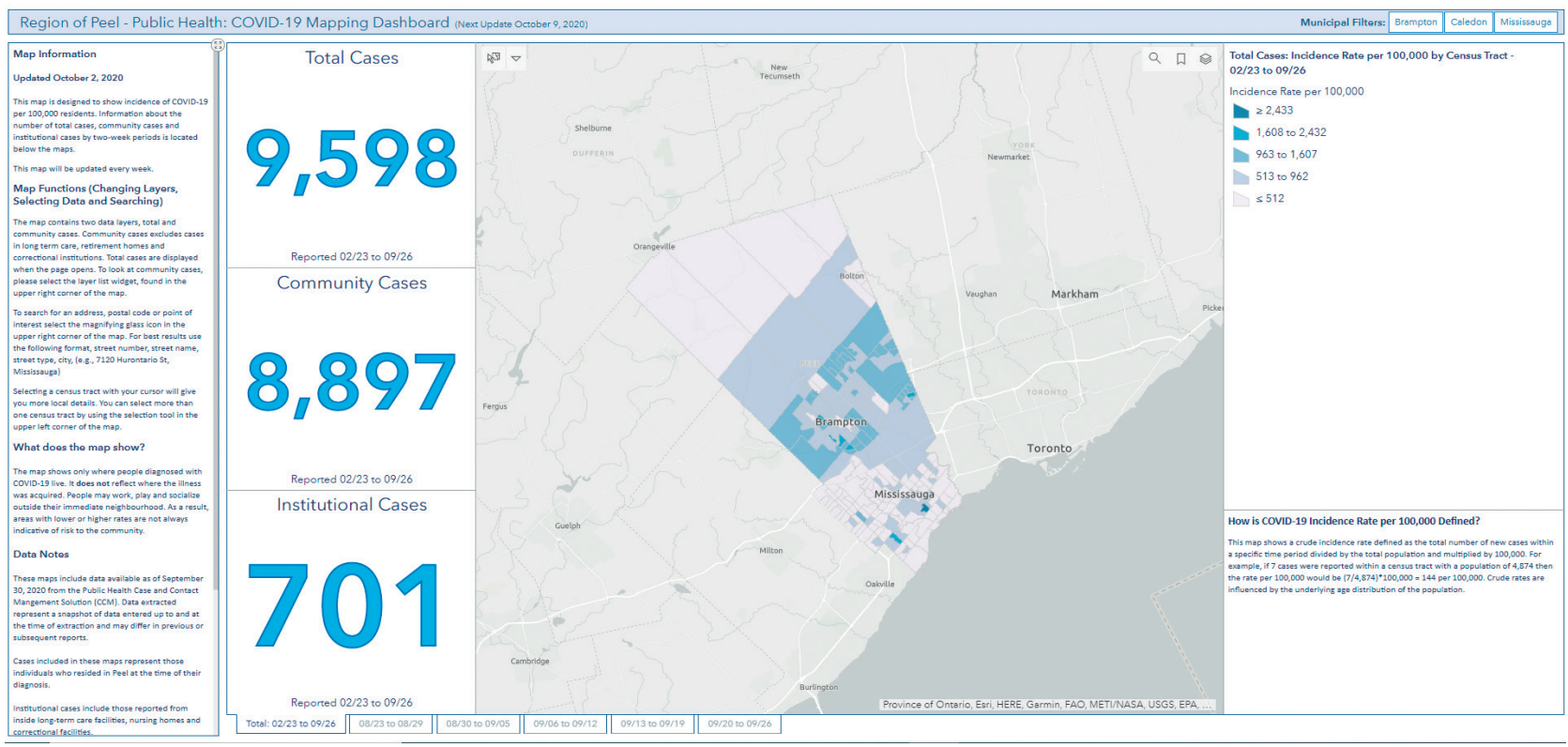

Figure 1 - Example screenshot of Peel's COVID-19 Mapping Dashboard

Source: Link to Region of Peel - Public Health COVID-19 Mapping Dashboard 
throughout the community, including lower-incidence rate areas of the Region, given the mobile nature of potential undetected cases.

In some jurisdictions that presented geographic data, the use of counts instead of rates led to public concerns around discrepancies between the total counts displayed on the mapping tool and the overall counts reported elsewhere on that health agency's website. Peel's reliance on relative rates prevented this issue while also mitigating privacy issues that might occur in neighbourhoods with a very small number of cases.

While the geographic mapping data was initially provided to address public interest in the information, it was ultimately used for planning targeted interventions in neighbourhoods with higher incidence rate relative to the Regional average. Besides supporting hypothesis generation in epidemiologic analysis as to drivers behind the patterns observed, the tool also assisted the roll out of mobile testing by the provincial government during the summer months. Specific neighbourhoods with higher incidence rates were identified for "pop-up" mobile testing.

The tool was not without limitations and logistical challenges. Updates on a biweekly and later weekly basis raised some criticism from members of the public who had been looking for a real-time tool; this was mitigated by ex- plaining that case counts and distribution were not changing more rapidly than the interval selected. The deployment of the tool during the pandemic response required significant support from digital services and privacy, while also drawing on expertise from epidemiologists and analysts, which was primarily committed to the investigation and tracking of outbreaks. Finally, the importance of messaging to caveat and address stigma, discrimination, and behaviour changes was absolutely critical.

\section{CONCLUSION}

Overall, the reaction to Peel Public Health's specific COVID-19 geographic reporting tool has been positive, with many concerns and limitations mitigated through careful messaging and management. Given the ongoing pandemic response and the broader interest from the public around more and more detailed COVID-19 data, it is important for public health agencies to set expectations around the nature of data disclosure, privacy, and confidentiality. Clarity in these expectations will support the protection of personal health information and the communication of risk where a public exposure has occurred, which will ultimately protect patients and communities from the myriad impacts of COVID-19.

\section{REFERENCES}

1. Liu Q, Liu W, Sha D, Kumar S, Chang E, Arora V, et al. An environmental data collection for COVID-19 pandemic research. Data. 2020;5:68.

2. Blomberg N, Lauer KB. Connecting data, tools and people across Europe: ELIXIR's response to the COVID-19 pandemic. Eur J Hum Genet. 2020;28:719-23.

3. Bromley L. Toronto Public Health releases new socio-demographic COVID-19 data. City of Toronto; 2020. [accessed 2020 Sep 1]. Available from: https://www.toronto.ca/news/toronto-public-health-releases-newsocio-demographic-covid-19-data/.

4. Britneff B. Coronavirus: 'incomplete' data for Canada hurts ability to model pandemic, scientists say. Global News 2020. [accessed YEAR MONTH DAY]. Available from: https://globalnews.ca/news/6825938/ coronavirus-incomplete-data-pandemic-modelling-scientists/.

5. Region of Peel. Population Growth. [accessed 2020 Aug 31]. Available from: https://www.peelregion.ca/strategicplan/20-year-outcomes/ population-growth.asp.

6. Region of Peel. Peel COVID-19 Weekly Epidemiologic Update. (Peel Health Surveillance). 2020. [accessed 2020 Aug 31] Available from: https://www.peelregion.ca/health/professionals/pdfs/COVID-19/epiupdate-20-08-28.pdf.

7. Region of Peel. COVID-19 for health professionals. [accessed 2020 Aug 31]. Available from: https://www.peelregion.ca/health-professionals/ covid-19/\#Itcrh.

8. Region of Peel. Cases of COVID-19 in Peel. 2020. [accessed 2020 Aug 31]. Available from: https://peelregion.ca/coronavirus/case-status/.

9. Brewer CA, Pickle L. Evaluation of methods for classifying epidemiological data on choropleth maps in series. Ann Assoc Am Geogr. 2002;92:662-81.

10. Census tract: Detailed definition.2018. [accessed 2020 Oct 8]. Available from: https://www150.statcan.gc.ca/n1/pub/92-195-x/2011001/geo/ctsr/def-eng.htm

11. Richards TB, Berkowitz Z, Thomas CC, Foster SL, Gardner A, King JB, et al. Choropleth map design for cancer incidence, Part 1. Prev Chronic Dis. 2009. [accessed 2020 Aug 30]. Available from: https://www.ncbi. nlm.nih.gov/pmc/articles/PMC2811518/.

12. Gregorio DI, DeChello LM, Samociuk $H$, Kulldorff M. Lumping or splitting: seeking the preferred areal unit for health geography studies. Int J Health Geogr. 2005;4:6.

13. Sui DZ, Holt JB. Visualizing and analysing Public-Health data using value-by-area cartograms: toward a new synthetic framework. Cartogr Int J Geogr Inf Geovisualization. 2008;43:3-20.

14. Sun $M$, Wong $D$, Kronenfeld $B$. A heuristic multi-criteria classification approach incorporating data quality information for choropleth mapping. Cartogr Geogr Inf Sci. 2017;44:246-58.

15. Hwang M, Smith M. Integrating publicly available web mapping tools for cartographic visualization of community food insecurity: a prototype. GeoJournal. 2012;77:47-62.

16. ArcGIS Online. ArcGIS Online, Cloud-Based GIS Mapping Software. [accessed 2020 Aug 31]. Available from: https://www.esri.com/en-us/ arcgis/products/arcgis-online/overview.

17. Lee D, Lee J. Testing on the move: South Korea's rapid response to the COVID-19 pandemic. Transp Res Interdiscip Perspect. 2020;5:100111. 